\title{
Correction to: First report of gray mold on Ocimum basilicum var. thyrsiflora caused by Botrytis cinerea in Japan
}

\author{
Jamjan Meeboon $^{1}$ - Makoto Shinohara ${ }^{1}$ \\ Published online: 20 November 2020 \\ (C) Società Italiana di Patologia Vegetale (S.I.Pa.V.) 2020
}

\section{Correction to: Journal of Plant Pathology https://doi.org/10.1007/s42161-020-00617-z}

The original article was published with textual errors the author group would like to have changed. These changes are as follows:

1) The title should be read:

First report of gray mold on Ocimum basilicum var. thyrsiflora caused by Botrytis cinerea in Japan.

2) The paragraph:

Association of sweet basil with $B$. cinerea has been reported in Greece, Hungary, Italy, Chile, Turkey and Poland (Farr and Rossman 2019) but not in Japan. This is the first report of gray mold on sweet basil in Japan.

should be noted as follows:
Association of basil with $B$. cinerea has been reported in Greece, Hungary, Italy, Chile, Turkey and Poland (Farr and Rossman 2019) and in Japan (Takeuchi et al. 1995). However, this is the first report of gray mold on Ocimum basilicum var. thyrsiflora in Japan.

3) The authors request the following reference to be added and noted:

- Takeuchi J, Hiromichi H, Hirano T (1995) Gray mold of some garden plants in Tokyo is caused by Botrytis cinerea Persoon. Proceedings of the Kanto-Tosan Plant Protection Society, N. 42 (in Japanese).

Publisher's note Springer Nature remains neutral with regard to jurisdictional claims in published maps and institutional affiliations.

The online version of the original article can be found at https://doi.org/ 10.1007/s42161-020-00617-Z

Jamjan Meeboon

jamjanm@yahoo.com; mibunj714@affrc.go.jp

Institute of Vegetable and Floriculture Science, National Agriculture and Food Research Organization, Tsu, Mie 514-2392, Japan 